\title{
Electrochemical studies, Monte Carlo simulation and DFT of a new composite - pentaglycidyl ether pentaphenoxy of phosphorus - crosslinked and hybrid in its coating behavior on E24 carbon steel in $3.5 \% \mathrm{NaCl}$
}

\author{
R. Hsissou ${ }^{a}$, F. Benhiba ${ }^{b}$, A. Zarrouk Za, $^{c}$, H. Oudda ${ }^{b}$ and A. Elharfi ${ }^{a}$ \\ ${ }^{a}$ Laboratory of Organic, Organometalic and Theoretical Synthesis. Faculté des Sciences; \\ Université Ibn Tofail, Kenitra, Morocco \\ ${ }^{b}$ Laboratory of Materials, Electrochemistry and Environment, Faculty of Sciences; \\ Université Ibn Tofail, Kenitra, Morocco \\ ${ }^{c}$ Regional Centre of Matters for Education and Formation (CRMEF), \\ Avenue Allal Al Fassi, Madinat Al Irfane BP 6210 Rabat, Morocco
}

Received March 20, 2018; accepted August 25, 2020

\begin{abstract}
This work consists in applying and studying the new pentafunctional phosphoric polymeric architecture - pentaglycidyl ether pentaphenoxy phosphorus (PGEPPP) - on the behavior of its coating, in a marine environment. First, we applied the new macromolecular pentafunctional epoxide (PGEPPP) binder, crosslinked by methylene dianiline and formulated by a natural phosphate, to E24 carbon steel, in the presence of two formulations, F1 (PGEPPP/MDA) and F2 (PGEPPP/MDA/PN). Then, we have studied the behavior of the anticorrosive coating on the metal substrate, in $3.5 \% \mathrm{NaCl}$. Indeed, the gravimetric, stationary and transient electrochemical studies of the composite (PGEPPP/MDA/PN) are very interesting and reach maximum values which are equal to $94 \%, 95 \%$ and $91 \%$, respectively.

We then proceeded to the prediction of the quantum parameters of the new pentafunctional phosphorus epoxy resin; these parameters were calculated according to the method of the Theory of Functional Density (DFT), at the level of 6-311 G (d,p) basis sets. Finally, the results obtained by the Monte Carlo simulation are in very good agreement with the data of the DFT theory and with the experimental data.
\end{abstract}

Keywords: polymer, composite, coating, E24 carbon steel, electrochemical studies and theoretical study.

\section{Introduction}

Polymeric architectures are very important thermosetting macromolecular matrices, since they have been widely used in several industrial fields, such as electronics [1], landfilling of radioactive waste, aeronautics, space construction,

\footnotetext{
*Corresponding author. E-mail address: azarrouk@gmail.com
} 
inhibition and coating of metal objects [2, 3]. They result from numerous properties: thermal, mechanical, dielectric, morphological conductivity, physicochemical, viscosimetric and rheological [4-6]. However, their application as anticorrosive coatings remains a very interesting field to explore.

Currently, carbon steel and its alloys are the most used materials in the industrial field, because of their properties: electrical, dielectric, thermal, mechanical, etc. They can be corroded in aggressive media $\left(\mathrm{HCl}, \mathrm{H}_{3} \mathrm{PO}_{4}, \mathrm{H}_{2} \mathrm{SO}_{4}\right.$, etc.) [7]. In addition, there are several types of coatings, among which are organic polymers that play a very important role for metallic protection against corrosion $[8,9]$.

In this paper, we applied PGEPPP and its composite, studying its anticorrosive behavior on E24 carbon steel, in a marine environment. In this regard, we have utilized weight loss, electrochemical (EIS, Tafel) methods, UV-visible spectroscopy associated with DFT methodology and Monte Carlo simulations.

\section{Material and methods}

\section{Used products}

In our paper, we used the new phosphoric polyepoxide polymeric macromolecular binder, PGEPPP, of which semi-developed structure is shown in Fig. 1.

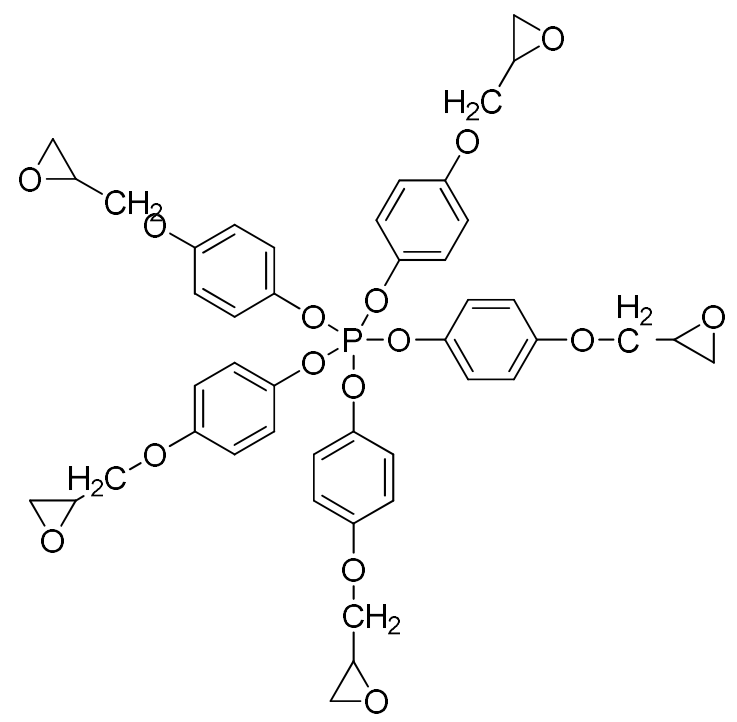

Figure 1. Semi-developed PGEPPP structure.

\section{Crosslinking PGEPPP with methylene dianiline}

Fig. 2 illustrates the three-dimensional structure of PGEPPP and that of the crosslinking reaction of the latter with the intermediate of methylene dianiline as a hardening agent.

\section{Calculation of the ratio of stoichiometric coefficients of PGEPPP resin}

In order to obtain optimal properties, we have hardened PGEPPP, in the presence of methylene dianiline as a hardener, at approximately stoichiometric amounts $[10,11]$. 


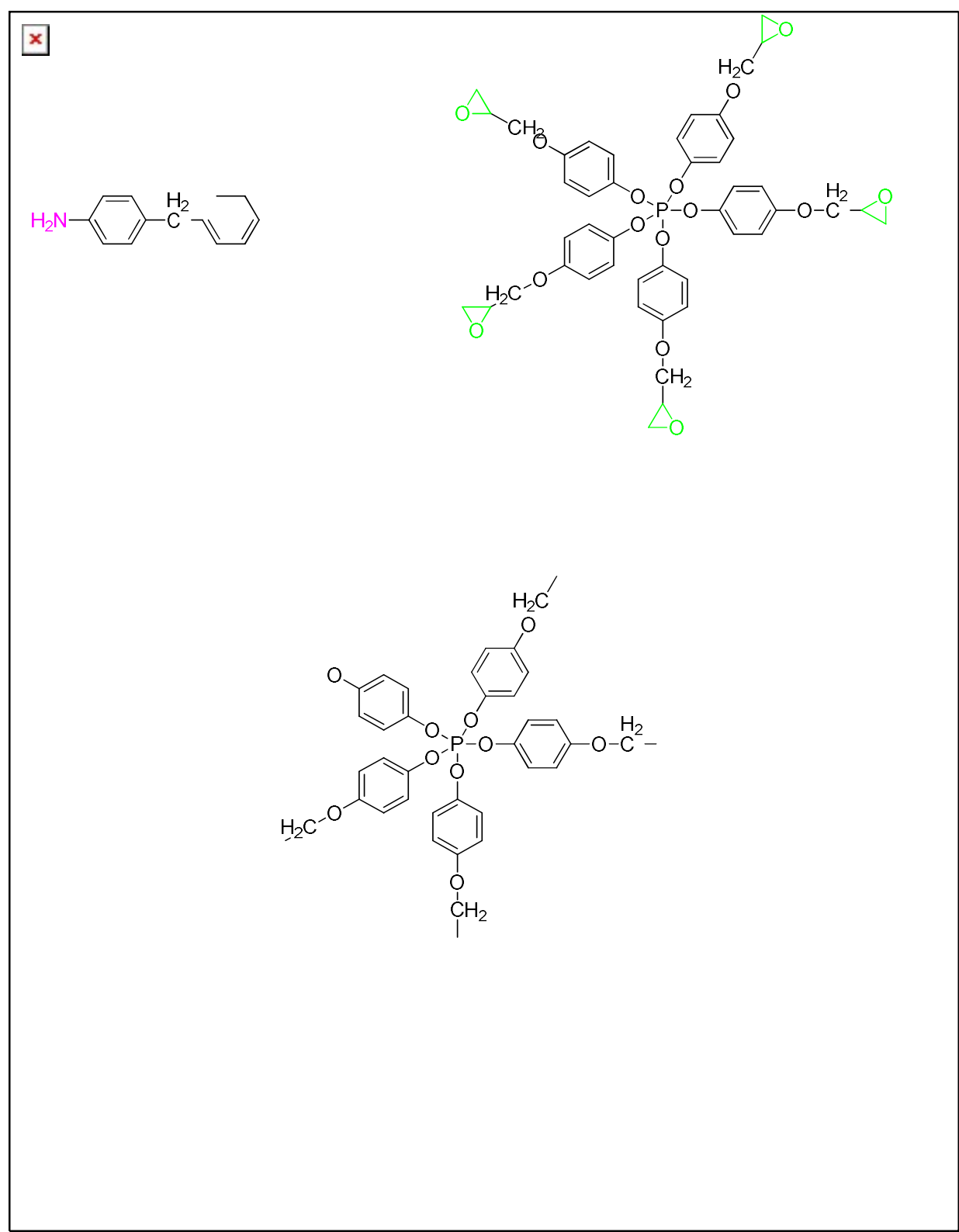

Figure 2. Crosslinking diagram of PGEPPP with methylene dianiline.

\section{Calculation of the epoxy equivalent weight (EEW)}

The epoxy equivalent weight was calculated using the following relationship:

$$
\mathrm{EEW}=\frac{\mathrm{M}_{\mathrm{W}}(\mathrm{PGEPPP})}{\mathrm{f}}
$$

where $\mathrm{f}$ is the functionality of the pentafunctional phosphoric epoxy resin.

$$
\begin{gathered}
\mathrm{EEW}=\frac{856}{5} \\
\mathrm{EEW}=171.2 \mathrm{~g} / \mathrm{eq}
\end{gathered}
$$


Calculation of the amine hydrogen equivalent weight (AHEW)

The amine hydrogen equivalent weight (AHEW) was calculated using the following relationships:

$$
\begin{aligned}
\text { AHEW } & =\frac{M_{\mathrm{W}}(\mathrm{MDA})}{\mathrm{f}} \\
\mathrm{AHEW} & =49.5 \mathrm{~g} / \mathrm{eq}
\end{aligned}
$$

\section{Calculation of the ratio by weight}

The weight ratio of the hardener (methylene dianiline) relative to PGEPPP was calculated in the majority of cases per 100 parts of resins or PHR (parts per hundred of resin):

$$
\begin{aligned}
& \text { PHR (Amine) }=\frac{\text { AHEW }}{\text { EEW }} \times 100 \\
& \text { PHR (Amine) }=\frac{49.5}{171.2} \times 100 \\
& \text { PHR (Amine) }=29 \mathrm{~g} / \mathrm{eq}
\end{aligned}
$$

From the calculation of the epoxy equivalent weight and of the amine hydrogen equivalent weight, $29 \mathrm{~g}$ of methylene dianiline were reacted per $100 \mathrm{~g}$ of PGEPPP.

\section{Calculation of the ratio to the quantity of the load}

The amount of charge of the desired natural phosphate was calculated according to the following equation:

$$
y \%=\frac{x}{\text { resin }+\mathrm{MDA}+\mathrm{x}}
$$

where $\mathrm{x}$ is the quantity of PGEPPP and $\mathrm{y}$ is the amount of the phosphate load.

\section{E24 carbon steel Coating with different formulations, F1 (PGEPPP/MDA) and F2 (PGEPPP/MDA/PN)}

The carbon steel sheets of $2.4 \mathrm{~cm} \times 0.9 \mathrm{~cm}$ were abraded with a series of emery paper SIC (600, 1000, 1200 and 1500), washed with distilled water and dried with hot air, before immersion in the corrosive solution. We distinguished two formulations.

Formulation 1 (PGEPPP/MDA) had a protocol which consists of preheating the stoichiometric amounts of the prepolymer and of the hardener. We mixed $1 \mathrm{~g}$ of PGEPPP and $0.29 \mathrm{~g}$ of methylene dianiline, and then stirred the mixture. Then we left it for about $30 \mathrm{~min}$ to homogenize it [12]. The formulation was applied to E24 carbon steel by using a film-producing rod. This coated plate was placed in an oven for 24 hours at $70{ }^{\circ} \mathrm{C}$, to crosslink the polymer deposited on the substrate. 
Formulation 2 (PGEPPP/MDA/PN) was submitted to the same previous protocol to the crosslinking reaction of the prepolymer, in the presence of methylene dianiline as a hardener, with the addition of $5 \%$ of the phosphate rock load.

\section{Weight loss corrosive test}

The weight loss allowed us to calculate the corrosion rate (w) expressed in $\mathrm{mg} \mathrm{cm} \mathrm{cm}^{-2} \mathrm{~h}^{-1}$. The corrosion rate can be determined, either by chemical analysis of the dissolved metal in a solution, or by gravimetric method, by measuring the weight of the sample, before and after exposure to the corrosive solution, applying equation 10 .

$$
\mathrm{w}=\frac{\left(\mathrm{m}_{1}-\mathrm{m}_{2}\right)}{\mathrm{S} \times \mathrm{t}}
$$

where $\mathrm{m}_{1}$ is the sample mass before corrosion, $\mathrm{m}_{2}$ is the sample mass after corrosion, $\mathrm{S}$ is the total sample surface, $\mathrm{t}$ is the corrosion time and $\mathrm{W}$ is the corrosion rate.

The coating protective efficacy was calculated from measurements of weight loss and of E24 carbon steel surface coverage, in the absence and presence of different formulations (PGEPPP/MDA and PGEPPP/MDA/PN), in 3.5\% NaCl, at $25^{\circ} \mathrm{C}$, after 6 hours of immersion in the corrosive solution.

The protective coating efficacy for E24 carbon steel corrosion was obtained according to equation 11 [13].

$$
\mathrm{IE}_{\mathrm{w}}(\%)=\left(1-\frac{\mathrm{W}_{\text {corr }}}{\mathrm{W}_{\text {corr }}^{0}}\right) \times 100
$$

where $\mathrm{W}_{\text {corr }}^{0}$ and $\mathrm{W}_{\text {corr }}$ are $\mathrm{E} 24$ carbon steel samples corrosion rates, without and with each a protective matrix, respectively.

The degree of surface coverage $(\theta)$ was calculated by using equation 12 [13].

$$
\theta=\left(1-\frac{\mathrm{W}_{\mathrm{corr}}}{\mathrm{W}_{\mathrm{corr}}^{0}}\right)
$$

\section{Electrochemical techniques}

The electrochemical measurements were obtained by means of an assembly of the electrochemical cell with three electrodes: a platinum wire as counter electrode, a saturated calomel reference electrode and a rectangular carbon steel working electrode. The contact surface with the corrosive solution was $1 \mathrm{~cm}^{2}$. Before each test, the working electrode was polished with sandpaper of 600 , 1000,1200 and 1500 grades.

The stationary measurements were carried out in potentiodynamic mode, by using a SP-200 Biologic Science Instruments potentiostat/galvanostat. The working electrode was previously immersed in the free corrosion potential for 30 min. During potentiodynamic study, $1 \mathrm{mV} / \mathrm{s}$ scan rate was selected. The determination of the electrochemical parameters ( $i_{c o r r}, E_{c o r r}, \beta_{c}$ and $\beta_{a}$ ) from the polarization curves was done by using a nonlinear regression by the Ec-Lab software. Thus, the coating efficiency, $\eta \%$, is determined from equation 13 . 


$$
\eta \%=\left(\frac{\mathrm{i}_{\text {corr }}^{0}-\mathrm{i}_{\text {corr }}}{\mathrm{i}_{\text {corr }}^{0}}\right) \times 100
$$

where $\mathrm{i}_{\text {corr }}^{0}$ and $\mathrm{i}_{\text {corr }}$ are, respectively, corrosion current densities of $\left(\mathrm{A} \mathrm{cm}^{-2}\right)$, without and with the different coating formulations.

$\beta_{\mathrm{c}}$ and $\beta_{\mathrm{a}}$ are, respectively, the Tafel constants of the cathodic and anodic reactions $\left(\mathrm{V}^{-1}\right)$. These constants are related to the Tafel slope $\beta(\mathrm{V} \mathrm{dec}-1)$ on the logarithmic scale, according to equation 14.

$$
\beta=\frac{\ln (10)}{b}=\frac{2.303}{b}
$$

Electrochemical impedance spectroscopy measurements were performed using the same apparatus, with a signal amplitude of $10 \mathrm{mV}$. The explored frequency domain varied from $100 \mathrm{KHz}$ to $10 \mathrm{mHz}$. The coating protection efficiency, $\eta \%$, was calculated using equation 15.

$$
\eta \%=\left(\frac{\mathrm{R}_{\mathrm{p}}-\mathrm{R}_{\mathrm{p}}^{0}}{\mathrm{R}_{\mathrm{p}}}\right) \times 100
$$

where $\mathrm{R}_{\mathrm{p}}^{0}$ and $\mathrm{R}_{\mathrm{p}}$ are, respectively, the polarization resistances in the absence and presence of different formulations.

\section{Quantum chemical calculation}

The computation of quantum chemistry has been widely used to study reaction mechanisms [14]. In this part of our work, we investigated the relationship between the quantum chemistry parameters of the pentafunctional resin, which were computed by the Functional Density Theory method, at the level of Becke-3-parameters-Lee-Yang-Parr, on the basis of $(6-311 \mathrm{G})[15,16]$. All these calculations were made by Gaussian 03. For this, we performed a theoretical calculation to determine the quantum chemical parameters, such as highest occupied molecular orbital energy ( $\left.\mathrm{E}_{\mathrm{HOMO}}\right)$, lowest unoccupied molecular orbital energy $\left(\mathrm{E}_{\mathrm{LUMO}}\right)$, gap energy $(\Delta \mathrm{E})$, dipole moment $(\mu)$, etc.

These $\mathrm{E}_{\text {HOMO }}$ and $\mathrm{E}_{\mathrm{LUMO}}$ molecular orbitals of the macromolecular matrix are respectively bound to ionization potential (IP) and electron affinity (EA), by the following relationships [17]:

$$
\begin{aligned}
& \mathrm{PI}=-\mathrm{E}_{\text {Hомо }} \\
& \mathrm{AE}=-\mathrm{E}_{\text {LUMO }}
\end{aligned}
$$

Gap energy is the difference between the energy of the lowest unoccupied molecular orbital (ELUMO) and the energy of the highest occupied molecular orbital (Еномо).

$$
\Delta \mathrm{E}=\mathrm{E}_{\text {LUMO }}-\mathrm{E}_{\text {HOMO }}
$$


The absolute chemical hardness $(\eta)$ can be evaluated by the following equation [16]:

$$
\eta=\frac{\Delta \mathrm{E}}{2}=\frac{\mathrm{E}_{\text {LUMO }}-\mathrm{E}_{\mathrm{HOMO}}}{2}
$$

The chemical sweetness $(\sigma)$, which describes the ability of an atom or a group of atoms to accept electrons, is calculated according to the following equation [17]:

$$
\sigma=\frac{1}{\eta}=-\frac{2}{\mathrm{E}_{\text {HOMO }}-\mathrm{E}_{\mathrm{LUMO}}}
$$

The electronegativity $(\chi)$ of PGEPPP was calculated by the following equation [17].

$$
\chi=\frac{\mathrm{PI}+\mathrm{AE}}{2}
$$

The electrophilic character, $\omega$, is a reactivity descriptor which allows a quantitative classification of a compound electrophilic nature, within a relative scale. We have proposed the electrophilic character as a measure of the lowering of the maximum energy, due to electrons flow between the donor and the acceptor, which is defined by the following relation:

$$
\omega=\frac{\chi^{2}}{2 \eta}
$$

Moreover, the number of transferred electrons $(\Delta N)$ was calculated according to the quantum chemical method by the following equation [18]:

$$
\Delta \mathrm{N}=\frac{\chi_{\mathrm{Fe}}-\chi_{\mathrm{inh}}}{2\left(\eta_{\mathrm{Fe}}+\eta_{\text {inh }}\right)}
$$

where $\chi_{\mathrm{Fe}}$ and $\chi_{\text {inh }}$ represent, respectively, the absolute electronegativity of iron and of the macromolecular resin, and $\eta_{\mathrm{Fe}}$ and $\eta_{\mathrm{inh}}$, respectively, denote the absolute hardness of iron and of the coating molecule. The theoretical value of $\chi_{\mathrm{Fe}}=7 \mathrm{eV}$ and $\eta_{\mathrm{Fe}}=0$ was used to calculate the number of transferred electrons [19].

\section{Monte Carlo simulation}

The computation was performed by using condensed phase optimized molecular fields for atomic simulation studies (COMPASS). The simulation was done for $\mathrm{Fe}$ (110) surface; this surface is considered the most stable in comparison with Fe (100) and Fe (111) surfaces [20]. The interaction between Fe (110) surface and PGEPPP was performed in a simulation box, with the size of $20.12 \times 20.12 \times$ $35.8 \AA$. Then, the Fe (110) plane was enlarged to a super-cell $(6,6)$, with periodic boundary conditions. A vacuum plate of $30 \AA$ was introduced on Fe (110)surface. 


\section{Results and discussion}

\section{Iron release by flame atomic absorption spectroscopy}

The protective efficacy values can also be determined by a chemical analysis of E24 carbon steel dissolved in a $3.5 \% \mathrm{NaCl}$ solution, in the presence of different formulations of PGEPPP resin, after 6 hours of immersion, at $298 \mathrm{~K}$. These are mentioned in Fig. 3.

The results of this figure show that the amount of iron dissolved in the marine solution decreases with the presence of different protective composites: respectively, $\mathrm{F} 1$ (PGEPPP/MDA) and $\mathrm{F}_{2}$ (PGEPPP/MDA/PN). In fact, the protective efficacy increases with $\mathrm{F} 1$ and $\mathrm{F} 2$ formulations, reaching a maximum value of $93 \%$, in the presence of the formulated composite (PGEPPP/MDA/PN).

\section{Gravimetric measurement}

Corrosion velocity and surface coverage values obtained from measurements of E24 carbon steel weight loss, for different behavioral formulations of PGEPPP resin coating, in $3.5 \% \mathrm{NaCl}$, at $298 \mathrm{~K}$, after 6 hours of immersion time, are shown in Fig. 4.

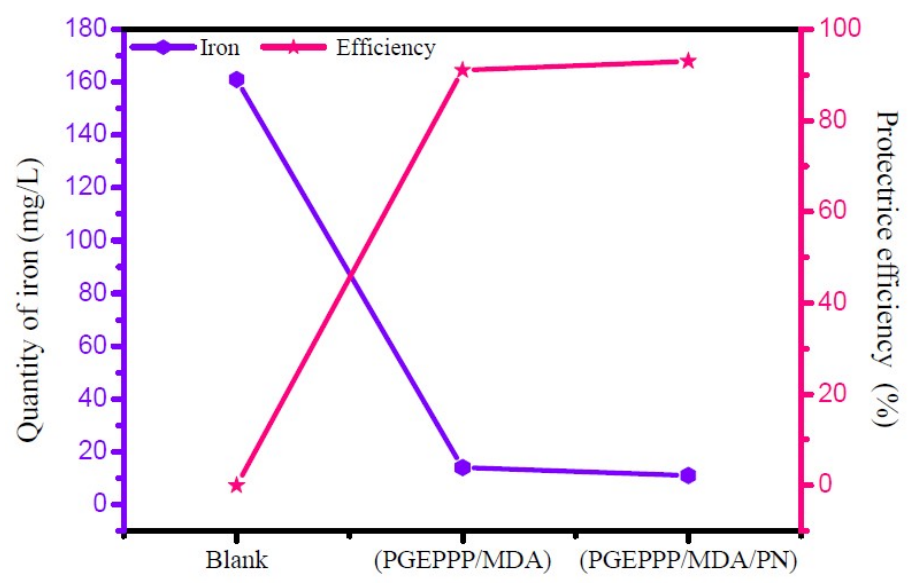

Figure 3. Quantity of iron and protective efficiency obtained by flame atomic absorption spectroscopy.

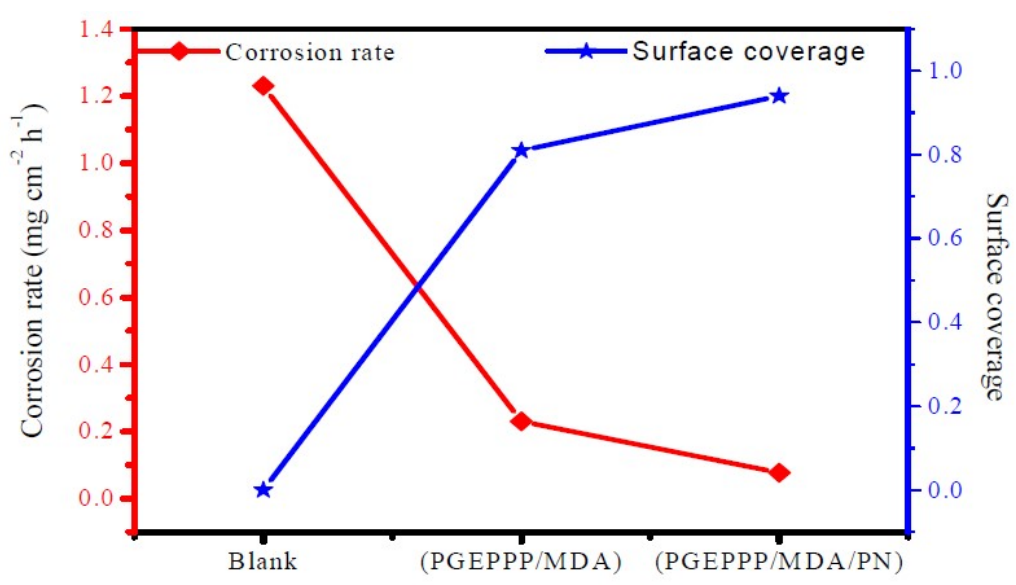

Figure 4. Corrosion rate and surface coverage. 
The results of Fig. 4 show that the corrosion rate decreased and that the surface coverage increased, with the different formulations of the crosslinked and formulated polymer. The maximum value of the upper coating coverage on the metal surface was obtained in the solution with the crosslinked and formulated polymer.

\section{Open-circuit potential}

Fig. 5 shows the evolution of the open circuit potential, as a function of time, in a solution of $3.5 \% \mathrm{NaCl}$, in the absence and presence of different formulations.

In the absence of PGEPPP/MDA and PGEPPP/MDA/PN formulations, $\mathrm{E}_{\text {corr }}$ shifted to more negative values, reaching the equilibrium value of $-0.51 \mathrm{~V}$.

Passing the potential to a more anodic direction is often associated with the formation of a protective film onto the electrode surface.

In the presence of different formulations (PGEPPP/MDA and PGEPPP/MDA/PN), the initial corrosion potential became more negative. The shifting of the potential to more negative values can occur, if the carbon steel anodic dissolution is accelerated by the studied polymers action, as well as by the decrease in the cathodic reaction.

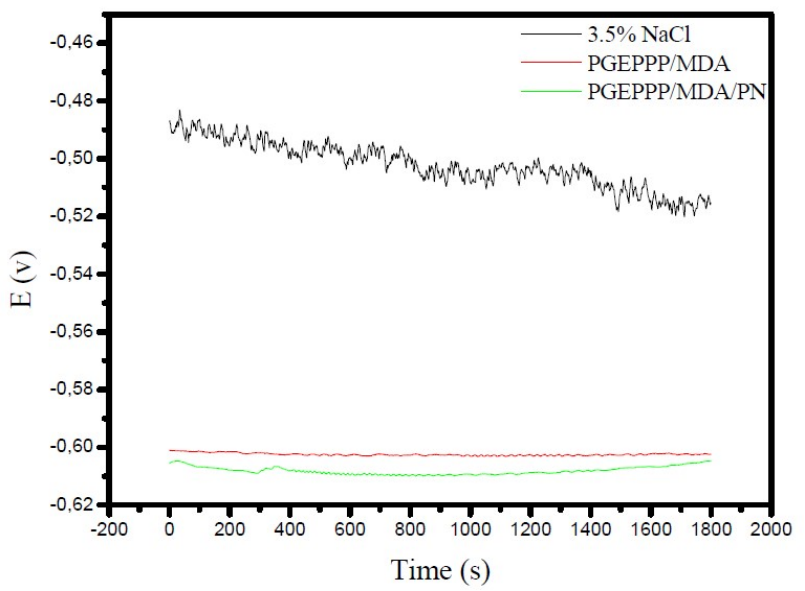

Figure 5. Evolution of carbon steel $\mathrm{E}_{\text {corr, }}$ in a $3.5 \% \mathrm{NaCl}$ solution, with and without the presence of different formulations.

\section{Polarization curves}

Fig. 6 shows the potentiodynamic polarization curves that represent the behavioral effect of E24 carbon steel coating, in a marine environment, by different formulations: F1 (PGEPPP/MDA) and F2 (PGEPPP/MDA/PN).

From Fig. 6, we found that, on the uncoated substrate control, the chloride anions and hydroxyl ions from the corrosive media directly attack the substrate, which induces direct corrosion.

The results in Table 1 show that the substrates coated by the different formulations studied in the corrosive solution led to a change in the corrosion potential $\left(\mathrm{E}_{\text {corr }}\right)$, in the cathode range, to negative values, and to a marked decrease in the current density for PGEPPP [21, 22]. 
The different electrochemical parameters associated with the polarization curves of E24 carbon steel immersed in a marine environment, in the absence and presence of various formulations, F1(PGEPPP/MDA) and F2 (PGEPPP/MDA/PN), are summarized in Table 1.

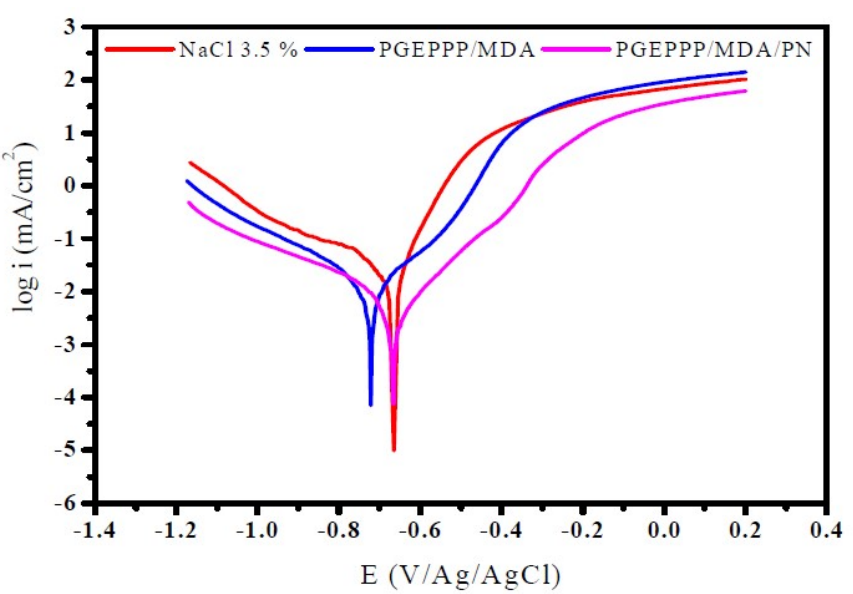

Figure 6. Polarization curves of E24 carbon steel, in the presence of the studied formulations, after $30 \mathrm{~min}$ immersion in a marine environment, at $298 \mathrm{~K}$.

Table 1. Different electrochemical parameters taken from polarization curves.

\begin{tabular}{llllll}
\hline Protective matrices & $\begin{array}{l}-\mathbf{E}_{\mathbf{c o r r}} \\
(\mathbf{m V} / \mathbf{A g} / \mathbf{A g C l})\end{array}$ & $\begin{array}{l}\mathbf{i}_{\text {corr }} \\
\left(\boldsymbol{\mu A} / \mathbf{c m}^{2}\right)\end{array}$ & $\begin{array}{l}\boldsymbol{\beta}_{\mathbf{c}} \\
(\mathbf{m V} / \mathbf{d e c})\end{array}$ & $\begin{array}{l}\boldsymbol{\beta a} \\
(\mathbf{m V} / \mathbf{d e c})\end{array}$ & $\begin{array}{l}\boldsymbol{\eta} \\
(\%)\end{array}$ \\
\hline Blank & 665 & 36.00 & 405 & 88.0 & - \\
\hline (PGEPPP/MDA) & 720 & 5.42 & 109 & 89.0 & 85 \\
\hline (PGEPPP/MDA/PN) & 667 & 1.94 & 83.6 & 97.8 & 95 \\
\hline
\end{tabular}

From the obtained results for the substrate coated with the F1 formulation (PGEPPP/MDA), immersed for $30 \mathrm{~min}$ in a marine environment, we noticed a relatively large diffusion of chloride ions and hydroxyl ions through the protective film.

The surface could have micropores by inducing primary corrosion translated by the corrosion current density, equal to $5.42 \mu \mathrm{A} / \mathrm{cm}^{2}$, and a protective efficiency that reached $86 \%$. This is explained by the acceleration of the metal cathodic and anodic dissolution $[23,24]$.

Furthermore, in the presence of the F2 formulation coating (PGEPPP/MDA/PN), on E24 carbon steel immersed in the corrosive solution for $30 \mathrm{~min}$, with phosphate rock as a filler, we have therefore found that the diffusion of corrosive species (chloride ions, $\mathrm{Cl}$, and hydroxyl ions, $\mathrm{OH}^{-}$) is slowed, because of the layer formed by the natural phosphate [25-27].

This indicates the decrease in the dissolution rate of the substrate coated with the F2 formulation. Thus, corrosion electrochemical parameters were $\mathrm{i}_{\text {corr }}=1.94$ $\mu \mathrm{A} / \mathrm{cm}^{2}$, and the coating efficiency reached a maximum value of $95 \%$.

The corrosion potential moved globally towards the cathode direction, after the addition of the $\mathrm{F}_{1}$ (PGEPPP/MDA) and $\mathrm{F}_{2}$ (PGEPPP/MDA/PN) protection matrices. 
The addition of $F_{1}$ (PGEPPP/MDA) and $F_{2}$ (PGEPPP/MDA/PN) formulations is accompanied by a clear decrease in the current density, both in the cathode and anode domains.

This allowed us to conclude that the F1 matrix acts as a cathodic protective coating and that the $\mathrm{F}_{2}$ matrix acts as a mixed protective coating [28].

In Table 1 , the values of the slope parameter of anodic Tafel $\left(\beta_{a}\right)$ are not significantly different, which indicates that the mechanism of carbon steel corrosion is not affected by the addition of these matrices.

\section{Electrochemical impedance spectroscopy}

Fig. 7 presents the results of the electrochemical impedance spectroscopy of E24 carbon steel submerged for $30 \mathrm{~min}$, before each open circuit measurement, in a marine environment, in the presence of different F1 (PGEPPP/MDA) and $\mathrm{F}_{2}$ (PGEPPP/MDA/PN) formulations. Indeed, we performed PGEPPP electrochemical impedance spectroscopy to confirm the stationary method results.

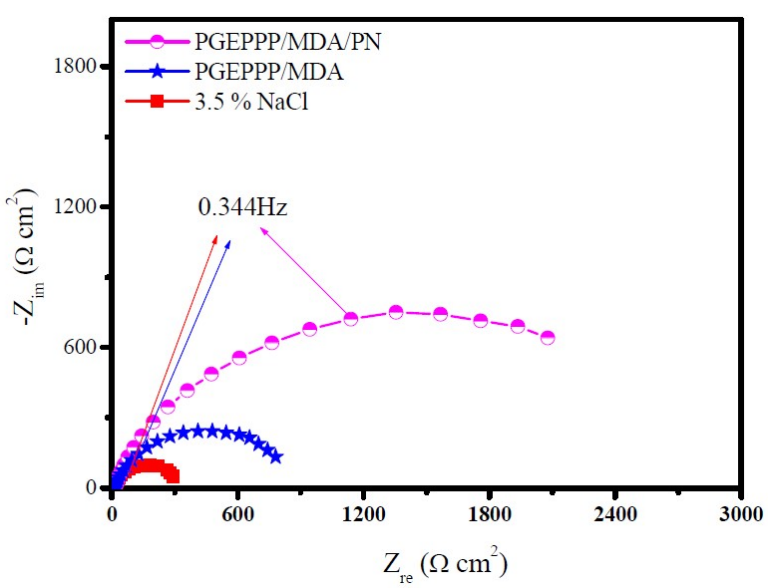

Figure 7. E24 carbon steel electrochemical impedance, after $30 \mathrm{~min}$ of immersion in $3.5 \% \mathrm{NaCl}$, in the presence of $298 \mathrm{~K}$ matrices $\left(\mathrm{F}_{0}, \mathrm{~F}_{1}\right.$ and $\left.\mathrm{F}_{2}\right)$.

The analysis of the results obtained from PGEPPP shows that it is formed by a high frequency capacitive loop attributed to the film effect. In fact, the greater the diameter of the half-circle, the better the corrosion resistance of the protective film will be $[28,29]$. The latter depends on the F1 coating formulation, and also increases with the presence of the natural phosphate feed incorporated into the F2 coating formulation. This indicates that the impedance of the coated substrates increases with the different formulations and that, therefore, the protective efficiencies increase. These results confirm those obtained by the stationary method.

The addition of different formulations (F1 and F2) improves the charge transfer resistance $\left(\mathrm{R}_{\mathrm{ct}}\right)$ values and decreases double layer capacitance $\left(\mathrm{C}_{\mathrm{dl}}\right)$ values. These observations clearly show that carbon steel corrosion in $3.5 \% \mathrm{NaCl}$ is controlled by the process of charge transfer, and that the behavior of the corrosion coating occurs through PGEPPP adsorption onto E24 carbon steel surface. The decrease in the double layer capacitance $\left(\mathrm{C}_{\mathrm{dl}}\right)$ values may result from a decrease in the 
local dielectric constant and/or from an increase in the density of the current, the thickness of the electric double layer. We suggest that PGEPPP resin functions by adsorption at the substrate interface of the metal solution [30, 31]. The effectiveness of the phosphoric polymer as anticorrosive coating depends mainly on the size and active centers of the new macromolecular architecture (PGEPPP). Improved performance of the polyepoxide prepolymer (PGEPPP) as a coating can be attributed to the structures of the epoxide groups and to the larger sizes of the pentafunctional macromolecular matrix. Indeed, the largest half circle in the Nyquist diagram of the E2 coating formulation indicates better corrosion resistance. This can be explained by the presence of a phosphate rock that is responsible for the higher corrosion resistance. From these results, we concluded that the values of the polarization resistors of the polyepoxide resin coating films (PGEPPP) are confirmatory with the results of the parameters from the potentiodynamic polarization curves.

Fig. 8 presents the Bode diagrams of E24 carbon steel coating behavior, in a marine environment, with the novel phosphorus pentafunctional epoxy resin (PGEPPP), in the presence of different formulations $\left(\mathrm{F}_{0}, \mathrm{~F}_{1}\right.$ and $\left.\mathrm{F}_{2}\right)$.

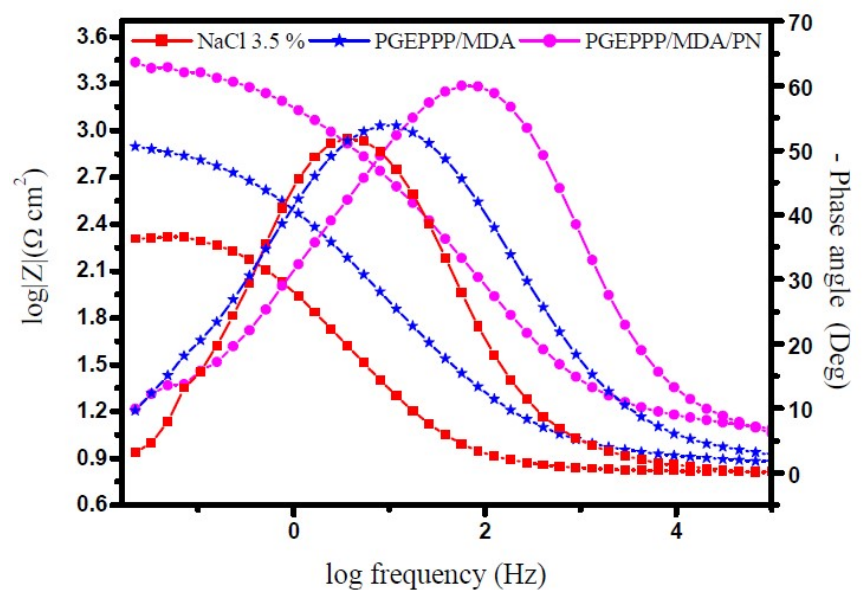

Figure 8. Bode diagram of the pentafunctional resin (PGEPPP) at different formulations, after $30 \mathrm{~min}$ of immersion in $3.5 \% \mathrm{NaCl}$, at $298 \mathrm{~K}$.

From Fig. 8, we have shown that the phase angles increase with the different protection formulations $\left(\mathrm{F}_{0}, \mathrm{~F}_{1}\right.$ and $\left.\mathrm{F}_{2}\right)$. This increase in phase angles confirms a higher protection in the presence of the crosslinked polymer, and then of the natural phosphate. From this phase angle diagram, we have shown that there are three frequency domains: the high frequencies, the intermediate frequencies and the low frequencies. At a high frequency, the phase angle values are approximately equal to zero. This indicates that the electrode behavior corresponds to the solution resistance. For intermediate frequencies, the phase angle is close to $60^{\circ}$, and a linear relation between $\log |Z|$ as a function of $\log (f)$, with a slope close to -1 , was observed. In fact, the phase angle values obtained from the phase angle $(Z)$ versus $\log$ (frequency) curves of the different protective formulations, $\mathrm{F}_{0}, \mathrm{~F}_{1}$ and $\mathrm{F}_{2}$, are, respectively, equal to $52^{\circ}, 54^{\circ}$ and $60^{\circ}$. Also, the values of the linear relation of $\log |\mathrm{Z}|$ depending on the $\log$ (frequency) ranged from -0.60 to -0.80 , for the different coating formulations $\left(F_{0}, F_{1}\right.$ and $\left.F_{2}\right)$. This 
could be explained by the non-ideal structure of the metal/solution interface. This capacitive behavior of the coating shows intermediate frequencies. Finally, for low frequencies, the increase in the impedance absolute values further confirms the greater protection with different coating formulations on E24 carbon steel. These results confirm those of electrochemical impedance spectroscopy [32 and 33].

Moreover, the shapes of the curves presented in the Nyquist and Bode diagrams show a capacitive behavior at the interface, and the existence of an equivalent electrical circuit (Fig. 9), which contains a constant phase element that is unique in the field metal/solution interface, in all the frequencies examined. This is due to the interpretation of the information on the coating behavior properties or on the metal surface corrosion. This circuit is composed of electrolyte resistance $(\mathrm{Rs})$, charge transfer resistance $\left(\mathrm{R}_{\mathrm{ct}}\right)$, double layer capacity $\left(\mathrm{C}_{\mathrm{dl}}\right)$, coating film capacity $\left(C_{f}\right)$ and film resistance coating $\left(R_{f}\right)$.

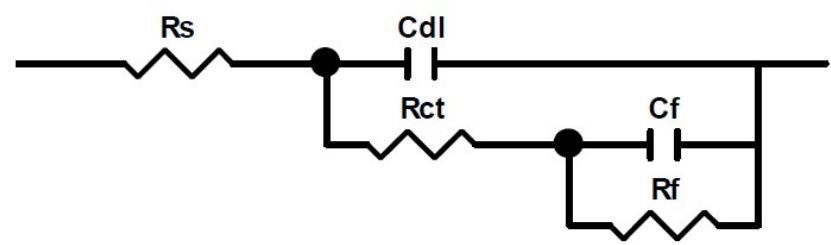

Figure 9. Equivalent electrical circuit of the impedance diagrams obtained for the pentafunctional resin, in the presence of different formulations $\left(\mathrm{F}_{0}, \mathrm{~F}_{1}\right.$ and $\left.\mathrm{F}_{2}\right)$.

The different values of the electrochemical impedance parameters, and the resulting efficiency for PGEPPP, in the presence of the various coating formulations $\left(\mathrm{F}_{0}, \mathrm{~F}_{1}\right.$ and $\left.\mathrm{F}_{2}\right)$, are grouped in Table 2 .

Table 2. Various electrochemical parameters of the phosphorus epoxy prepolymer taken from Nyquist diagrams.

\begin{tabular}{lllllll}
\hline Protective matrices & $\begin{array}{l}\mathbf{R}_{\mathbf{s}} \\
\left(\mathbf{\Omega} \mathbf{~ c m}^{2}\right)\end{array}$ & $\begin{array}{l}\mathbf{R}_{\mathbf{c t}} \\
\left(\mathbf{\Omega} \mathbf{~ c m}^{2}\right)\end{array}$ & $\begin{array}{l}\mathbf{C}_{\mathrm{dl}} \\
\left(\boldsymbol{\mu} \mathbf{F} / \mathbf{c m}^{2}\right)\end{array}$ & $\begin{array}{l}\mathbf{C}_{\mathbf{f}} \\
\left(\boldsymbol{\mu} \mathbf{F} / \mathbf{c m}^{2}\right)\end{array}$ & $\begin{array}{l}\mathbf{R}_{\mathbf{p}} \\
\left(\mathbf{\Omega} \mathbf{~ c m}^{2}\right)\end{array}$ & $\begin{array}{l}\mathbf{\eta} \\
(\mathbf{\%})\end{array}$ \\
\hline $\mathbf{F}_{\mathbf{0}}(\mathbf{N a C l ~ 3 . 5 \% )}$ & 6.5 & 2.4 & 1253 & 935 & 218 & - \\
\hline $\mathbf{F}_{\mathbf{1}}(\mathbf{P G E P P P / M D A})$ & 7.8 & 280 & 752 & 35 & 778 & 72 \\
\hline $\mathbf{F}_{\mathbf{2}}(\mathbf{P G E P P P / M D A} / \mathbf{P N})$ & 13 & 1383 & 79 & 7 & 2534 & 91 \\
\hline
\end{tabular}

From Table 2, we conclude that polarization resistance values of the coating film for PBEPPP, with different protection formulations $\left(\mathrm{F}_{1}\right.$ and $\left.\mathrm{F}_{2}\right)$, are confirmatory with the results of the parameters from potentiodynamic polarization curves.

\section{UV-visible spectroscopy}

Fig. 10 shows the UV-visible spectroscopy of the composite (PGEPPP/MDA/PN) dissolved in the corrosive solution of $3.5 \% \mathrm{NaCl}$.

The absorption of monochromatic light is an appropriate method for the characterization of complex ions in a solution; the absorption of light is proportional to the concentration of the absorbing species in the solution [34]. This is due to the amount of the cationic metal dissolved in the solution on the 
metal surface; this technique was conducted, in the present study, to confirm the possibility of a complex formation [iron-coating].

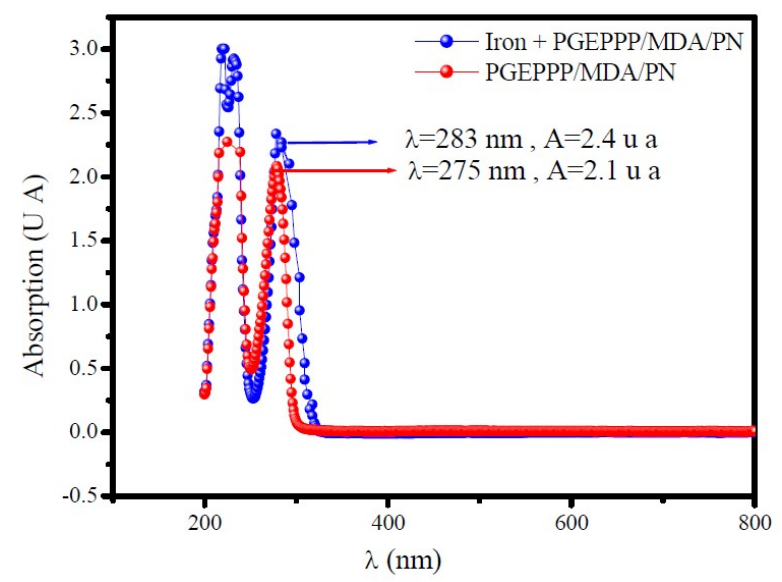

Figure 10. Absorption spectrum of the composite (PGEPPP/MDAMPN).

The electron absorption spectra of the composite (PGEPPP/MDA/PN) in the solution, before and after the immersion of E24 carbon steel in the marine solution, during 6 hours, show the existence of the visible $275 \mathrm{~nm}$ and $283 \mathrm{~nm}$ absorption bands, respectively. A change in the position of the maximum absorption indicates the formation of a complex between the two species in the solution, as reported in literature $[35,36]$. These experimental results are a strong proof of the possibility of a complex formation between the iron ion and the composite (PGEPPP/MDA/PN), in 3.5\% NaCl.

\section{Quantum calculation of pentafunctional polymer reactivity}

Experimental results, concerning E24 carbon steel coating behavior in a marine environment, obtained by flame atomic absorption, gravimetric studies and electrochemical studies, have simultaneously shown that the protective efficacy by the different formulations, F1 (PGEPPP/MDA) and F2 (PGEPPP/MDA/PN), resulting from the new pentafunctional phosphorus macromolecular resin, pentaglycidyl ether pentaphenoxy of phosphorus (PGEPPP), is very good.

To confirm the adhesion sites of the new epoxy polymer on the substrate which are responsible for the experimental results found above, we proceeded to the quantum chemistry calculation study, using Gaussain $03 \mathrm{~W}$ software.

In order to calculate the quantum chemistry parameters of the phosphorus polyepoxide resin, we have studied several descriptors on the electronic steric basis. The calculation of different descriptors was performed by Density Functional of Theory, at the level of Becke-3-parameters-Lee-Yang-Parr, on the basis of $6-311 \mathrm{G}(\mathrm{d}, \mathrm{p})$. The optimized geometric structure and density distribution of EHOMO and ELUMO electrons is shown in Fig. 11.

From Fig. 11, we observed that the HOMO electron density is located, respectively, on the aromatic ring surface and on the epoxy group surface of the phosphorus pentafunctional (PGEPPP) resin. On the other hand, the LUMO electron density is located, respectively, around the surface of the central phosphorus atom and on the surface of the oxygen atom directly connected to the 
phosphorus atom. The quantum chemistry parameters calculated to explain the reactivity of the electronegative and electropositive sites of the pentafunctional macromolecular phosphoric resin, PGEPPP, are grouped in Table 3.

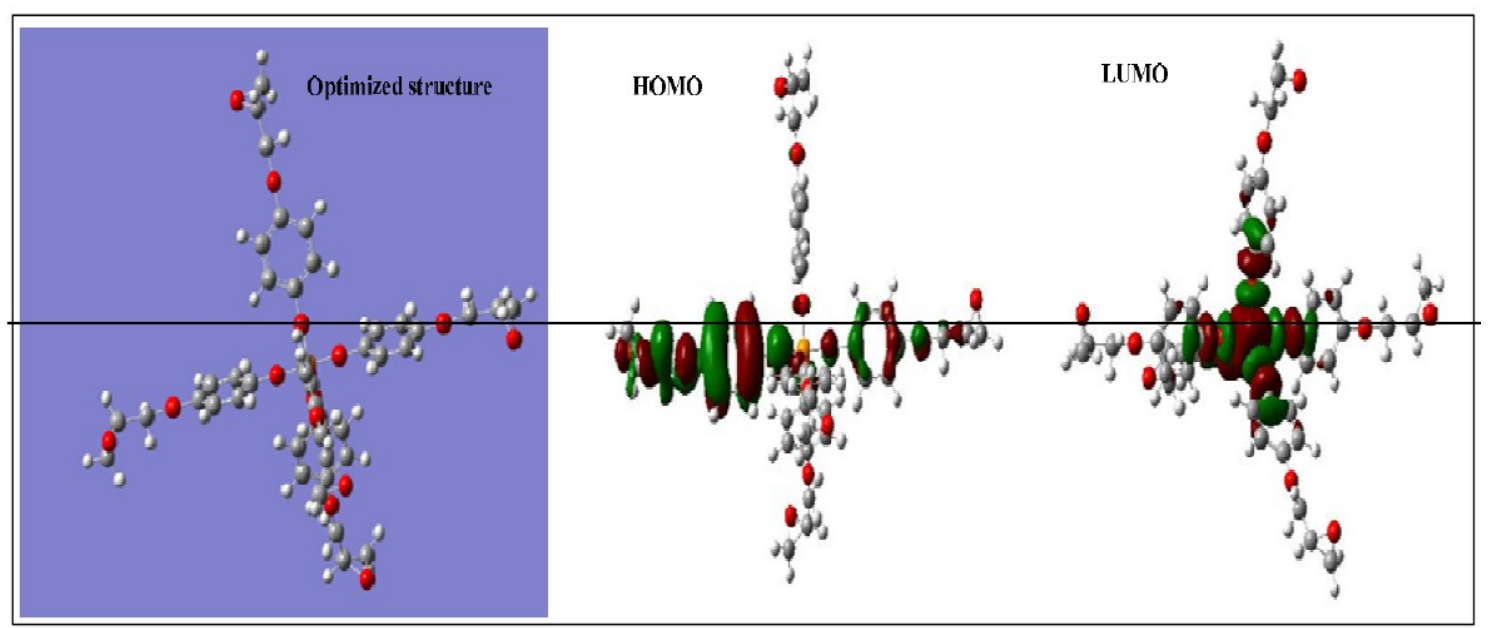

Figure 11. Optimized structure, HOMO and LUMO orbitals of pentafunctional phosphorus resin, PGEPPP.

Table 3. Different parameters of quantum chemistry of PGEPPP.

\begin{tabular}{cccccccccc}
\hline $\begin{array}{c}\text { Quantum } \\
\text { parameters }\end{array}$ & $\begin{array}{c}\mathbf{E}_{\text {Hомо }} \\
(\mathbf{e V})\end{array}$ & $\begin{array}{c}\mathbf{E}_{\text {LUMO }} \\
(\mathbf{e V})\end{array}$ & $\begin{array}{c}\Delta \mathbf{E} \text { gap } \\
(\mathbf{e V})\end{array}$ & $\begin{array}{c}\boldsymbol{\mu} \\
(\mathbf{D e b y e})\end{array}$ & $\begin{array}{c}\boldsymbol{\eta} \\
(\mathbf{e V})\end{array}$ & $\begin{array}{c}\mathbf{\Sigma} \\
\left(\mathbf{e V}^{-1}\right)\end{array}$ & $\begin{array}{c}\boldsymbol{(} \\
(\mathbf{e V})\end{array}$ & $\begin{array}{c}\boldsymbol{\omega} \\
(\mathbf{e V})\end{array}$ & $\begin{array}{c}\Delta \mathbf{N} \\
(\mathbf{e V})\end{array}$ \\
\hline Values & -5.827 & -4.023 & 1.804 & 3.788 & 0.902 & 1.108 & 4.925 & 13 & 1.135 \\
\hline
\end{tabular}

The highest occupied molecular orbital energy $\left(\mathrm{E}_{\text {номо }}\right)$ generally describes the ability of a molecule to donate electrons. A large value of the HOMO orbital energy facilitates the tendency of the resin to yield electrons to electron accepting species with unoccupied molecular orbitals, whose energy level is low. Indeed, the energy of the lower unoccupied molecular orbital $\left(\mathrm{E}_{\mathrm{LUMO}}\right)$ is related to the ability of a molecule to accept electrons; a low value of LUMO energy means that the pentafunctional macromolecular phosphorus resin certainly accepts electrons [37]. Thus, the adsorption performance of the coating matrix onto the metal surface increases when the gap energy is lower [38]. In this context, the results in Table 3 indicate that PGEPPP HOMO (-5.827 eV) and LUMO (4.023 $\mathrm{eV})$ high values show good protective efficacy. In fact, the high ionization energy indicates a high stability of the studied matrix [39].

The calculated hardness $(\eta)$ and softness $(\sigma)$ values are shown in Table 3, respectively. These show that PGEPPP can react easily with the metal surface. PGEPPP has good chemical reactivity with E24 carbon steel surface. This is due to the lowest hardness $(0.902 \mathrm{eV})$ and the highest softness $\left(1.108 \mathrm{eV}^{-1}\right)$ values of the PGEPPP resin.

From Table 3, we found that PGEPPP electrophile index $(\omega)$ is higher. For this, we concluded that PGEPPP can be composed of accepted electrons.

The number of transferred electrons $(\Delta \mathrm{N})$ is lower than 3.6. This indicates the tendency of a resin to give electrons to the metal surface. 
Through the $\Delta \mathrm{N}(1.135 \mathrm{eV})$ value of the pentafunctional phosphorus resin we observed that the latter is in agreement with Lukovit's study [40]. This result indicates that the quality of the protective film is well formed.

Furthermore, the use of dipole moment $(\mu)$ to support the protective effect of a corrosion inhibitor is often interpreted in two different ways: the high value of dipole moment for the studied matrix might favor strong dipole-dipole interactions between this polymer (PGEPPP) and the metallic surface; and the high value of $\chi$ for PGEPPP favors its highest protective adsorption observed from experimental studies.

\section{Monte Carlo simulation}

The study of the interactions between PGEPPP and the iron (110) metal surface was carried out by Monte Carlo simulation. The distribution of the adsorption energy for the Fe (110)/PGEPPP pair, by the adsorption localization model, is shown in Fig. 12. The latter shows that the adsorption energy of the new studied resin has reached a value of $-1154 \mathrm{Kcal} / \mathrm{mol}$. This indicates that the adsorption power onto the metal surface is suitable.

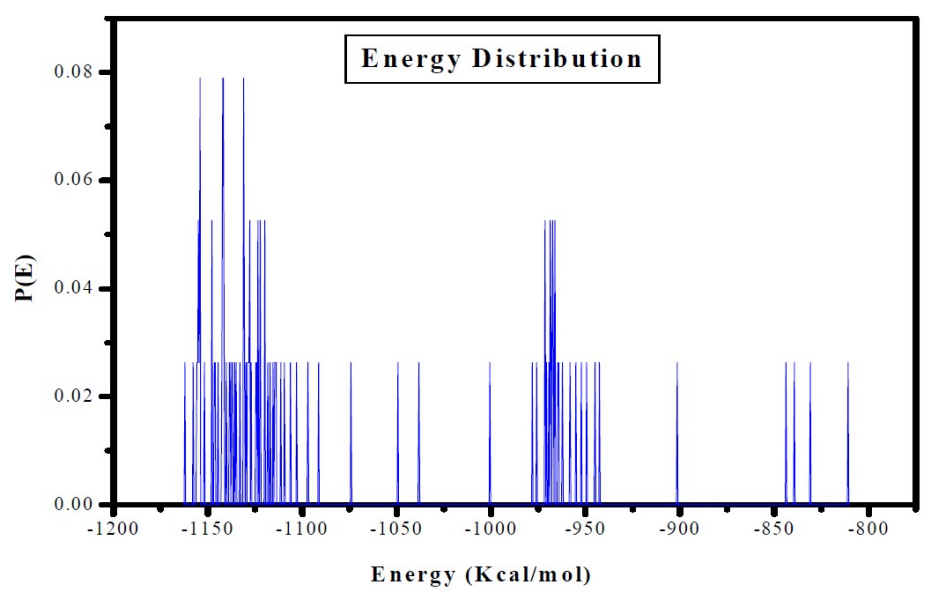

Figure 12. Distribution of the adsorption energy of the Fe (110)/PGEPPP system.

The side and top views of the best low energy, most stable adsorption configuration of the studied pentafunctional prepolymer, are shown in Fig. 13. As seen from Fig. 13, the adsorbed polymeric resin flats on the surface of interest and provides a larger area to stop the metal surface dissolution.

The adsorption density of the phosphoric polymer on the iron substrate surface (110) has been illustrated in Fig. 14. Based on the observations of Figs. 13 and 14 , we can confirm that the adsorption capacity on the iron surface is higher. It is obvious that the bridge and the hollow centers have the highest density of points. The results of the calculation of different energies, namely, the adsorption energy, the rigid adsorption energy, the strain energy and the desorption energy $(\mathrm{dEad} / \mathrm{dE})$ are summarized in Table 4. 

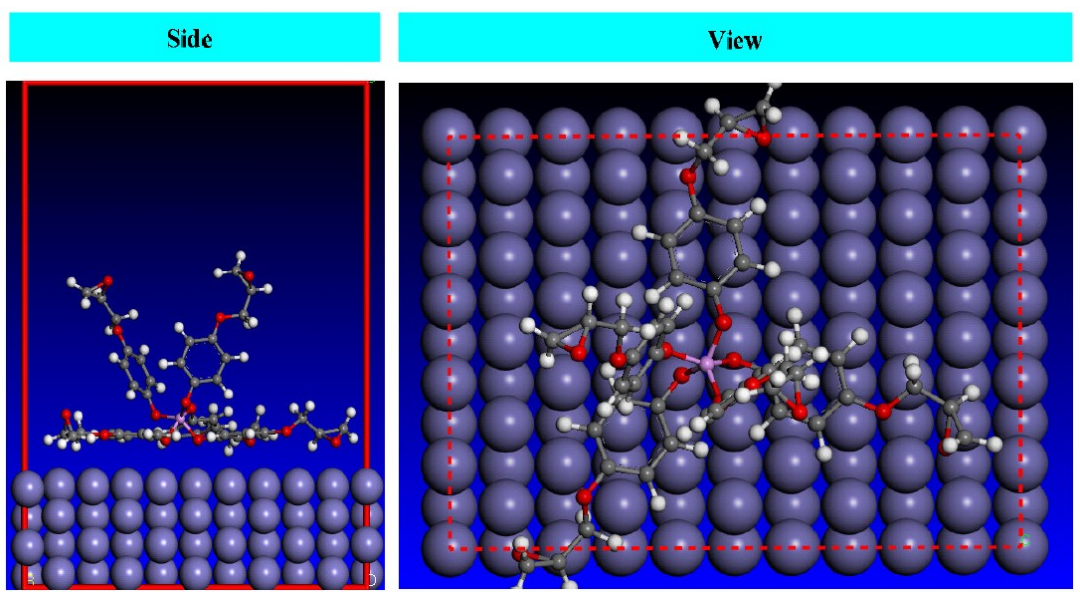

Figure 13. Lateral and upper views of the best adsorption configuration.

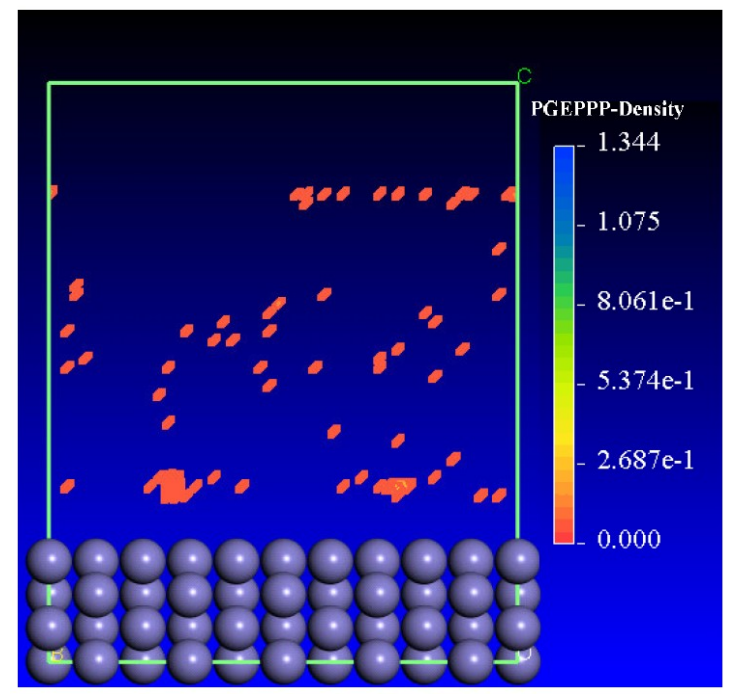

Figure 14. Density field for the iron interface (110/PGEPPP).

Table 4. Outputs and descriptors calculated by the Monte Carlo simulation on the iron surface (110). (All values in $\mathrm{kcal} / \mathrm{mol}$ ).

\begin{tabular}{llllll}
\hline Polymers & $\begin{array}{l}\text { Adsorption } \\
\text { energy }\end{array}$ & $\begin{array}{l}\text { Rigid adsorption } \\
\text { energy }\end{array}$ & $\begin{array}{l}\text { Strain } \\
\text { energy }\end{array}$ & $\begin{array}{l}\text { Desorption } \\
\text { energy }\end{array}$ \\
\hline $\mathrm{Fe}(110) / \mathrm{PGEPPP}$ & -1162.15 & -300.96 & -861.19 & -1162.15 \\
\hline
\end{tabular}

Table 4 shows that the adsorption energy value is negative, which indicates the spontaneity of the adsorption process of the phosphorus pentafunctional matrix (pentaglycidyl ether pentaphenoxy of phosphorus) [41]. On the other hand, the energy of desorption $(\mathrm{dEad} / \mathrm{dE})$ is the energy necessary to remove the adsorbate energy. As for the adsorption energy, it is considered as the algebraic sum of the rigid adsorption energy and the strain energy. The rigid adsorption energy thus reports the energy that is lost when the non-relaxed adsorbate components are adsorbed onto the iron surface. The deformation energy yields the lumpy energy when the adsorbed polymer is released on the metal surface being studied. 


\section{Conclusion}

In this work, we applied the pentafunctional phosphorus prepolymer, pentaglycidyl ether pentaphenoxy of phosphorus, for E24 carbon steel protection by the coating behavior process, resulting from different formulations based on a standard epoxy prepolymer (PGEPPP), methylene dianiline and natural phosphate.

The experimental results that we obtained in this study, concerning the coating of the metal substrate in the presence of different formulations, F1 (PGEPPP/MDA) and F2 (PGEPPP/MDA/PN), are grouped in three parts, namely the absorption of release of the metal substrate and gravimetric and also electrochemical measurements, which are confirmatory. Moreover, the prediction of the parameters of quantum chemistry by the Gaussian software 03, namely Eномо, Elumo, IP, EA, $\Delta \mathrm{E}, \mu, \sigma, \eta, \chi, \omega, \Delta \mathrm{N}$ and $\mathrm{E}_{\mathrm{T}}$, confirm the adhesion sites of the novel pentafunctional phosphorus epoxide polymeric architecture. Finally, Monte Carlo simulation confirms the DFT method.

\section{References}

1. Fetouaki S, Toufik M, Meghraoui H, et al. Phys Chem News. 2006;27:131.

2. EL Hilal B, Elharfi A. Int J Innov Appl Studies. 2014;7:729.

3. Hsissou R, Benassaoui H, Benhiba F, et al. J Chem Technol Metall. 2017;52:431.

4. Meenakshi KS, Sudhan EPJ. Arab J Chem. 2016;9:79.

5. Hsissou R, Dagdag O, EL Harfi A. Mor J Chem. 2015;3:791.

6. Hsissou R., Elharfi A. Mor J Chem. 2016;4:315.

7. Rosale B, Vera R, Morien G. Corros Sci. 1999;41:625.

8. Antonijevic MM, Petrovic MB. Int J Electrochem Sci. 2008;3:1.

9. Panah NB, Danaee I. Prog Org Coat. 2010;68:214.

10. Hsissou R, Bekhta A, El Harfi A. J Mater Environ Sci. 2017;8:603.

11. Hsissou R, El Bouchti M, El Harfi A. J Mater Environ Sci. 2017;8:4349.

12. Hsissou R, Bekhta A, Elharfi A, et al. Port Electrochim Acta. 2018;36:101.

13. Lodha SR, Pharma Reviews. 2008;6:1.

14. Ziraoui R, Meghraoui H, El Gouri M, et al. J Mater Environ Sci. 2010;1:213.

15. Ansari KR, Quraishi MA. J Taiwan Inst Chem E. 2015;54:145.

16. Becke DA. J Chem Phys. 1986;84:4524.

17. Saha SK, Hens A, Chowdhury AR, et al. Can Chem Trans 2014;2:489.

18. Tayebi H, Bourazmi H, Himmi B, et al. Der Pharm Chem. 2014;6:220.

19. Parr RG, Pearson RG. J Am Chem Soc. 1983;105:7512.

20. Guo L, Zhu S, Zhang S, et al. Corros Sci. 2014;87:366.

21. Hu L, Zhang S, Li W, et al. Corros Sci. 2010;52:2891.

22. Li W, Hu L, Zhang S, et al. Corros Sci. 2011;53:735.

23. Zubielewicz M, Gnot W. Prog Org Coat. 2004;49:358.

24. Amin MA, Khaled KF. Corros Sci. 2010;52:1194.

25. Rossenbeck B, Ebbinghaus P, Stratmann M, et al. Corros Sci. 2006;48:3703.

26. Liu S, Zhong Y, Jiang R, et al. Corros Sci. 2011;53:746.

27. Sherif EM, Park SM. Corros Sci. 2006;48:4065. 
28. Velrani S, Jeyaprabha B, Prakash P. Int J Innov Sci Eng Technol. 2014;1:57.

29. Wang B, Du M, Zhang J, et al. Corros Sci. 2011;53:353.

30. Scendo M. Corros Sci. 2007;49:373.

31. Li W, Zhao X, Liu F, et al. Corros Sci. 2008;50:3261.

32. Yurt A, Ulutas S, Dal H. Appl Surf Sci. 2006;253:919.

33. Galai M, El Gouri M, Dagdag O, et al. J Mater Environ Sci. 2016;7:1562.

34. Abboud Y, Abourriche A, Saffaj T, et al. Mater Chem Phys. 2007;105:1.

35. Obot IB, Obi-Egbedi NO, Eseola AO. Ind Eng Chem Res. 2011;50:2098.

36. Abboud Y, Abourriche A, Saffaj T, et al. Desalination. 2009;237:175.

37. Y1ld1z R. Corros Sci. 2015;90:544.

38. Khaled KF, Abdelshafi NS, El-Maghraby A, et al. J Mater Environ Sci. 2011;2:166.

39. Hsissou R, Khudhair M, Elharfi A. Mor J Chem. 2018;6:35.

40. Lukovits I, Kalman E, Zucchi F. Corr. 2001;57:3.

41. Saha SK, Murmu M, Murmu NC, et al. J Mol Liq. 2016;224:629. 